NASA Technical Memorandum 107258

AIAA-96-2881

\title{
Effects of Inlet Flow Conditions on Crossflow Jet Mixing
}

D.S. Liscinsky and B. True

United Technologies Research Center

East Hartford, Connecticut

J.D. Holdeman

Lewis Research Center

Cleveland, Ohio

Prepared for the

32nd Joint Propulsion Conference

cosponsored by AIAA, ASME, SAE, and ASEE

Lake Buena Vista, Florida, July 1-3, 1996

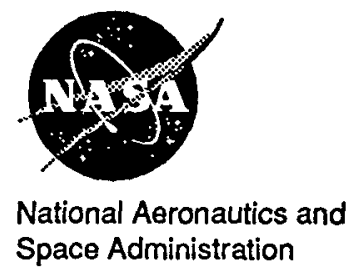




\title{
Effects of Inlet Flow Conditions on Crossflow Jet Mixing
}

\author{
D.S. Liscinsky* and B. True ${ }^{* *}$ \\ United Technologies Research Center \\ East Hartford, CT 06108 \\ J.D. Holdeman ${ }^{\dagger}$ \\ NASA Lewis Research Center \\ Cleveland, $\mathrm{OH} 44135$
}

\section{Abstract}

An experimental investigation of the effects of mainstream turbulence, mainstream swirl and non-symmetric mass addition has been conducted for the isothermal mixing of multiple jets injected into a confined rectangular crossflow. Jet penetration and mixing in the near field was studied using planar Mie scattering to measure time-averaged mixture fraction distributions. Orifice configurations were used that were optimized for mixing performance based on previous experimental and computational results for a homogeneous approach flow. Mixing effectiveness, determined using a spatial unmixedness parameter based on the variance of the mean jet concentration distributions, was found to be minimally affected by free-stream turbulence but significantly influenced by the addition of swirl to the mainstream. The results for non-symmetric mass addition indicate that the concentration distribution of the flowfield can be tailored if desired.

\section{Nomenclature}

$\begin{array}{ll}A_{j} & \begin{array}{l}\text { orifice area } \\ \text { cross-sectional area of mainstream duct } \\ \text { at injection location }\end{array} \\ A_{m} & (S / H) \sqrt{J} \\ C & M R /(1+M R) \\ c_{\text {avg }} & \begin{array}{l}\text { orifice discharge coefficient } \\ C_{d}\end{array} \\ d & \text { orifice diameter } \\ D R & \rho_{j} / \rho_{m} \\ H & \text { duct height }=5.08 \mathrm{~cm} \\ H_{e q} & \text { effective duct height }(\text { see page } 3) \\ J & \text { jet-to-mainstream momentum-flux ratio } \\ & =\left(\rho_{j} V_{j}^{2}\right) /\left(\rho_{m} V_{m}^{2}\right) \\ & =(M R)^{2} /\left[(D R)\left(A_{j} / A_{m}\right)^{2}\left(C_{d}\right)^{2}\right] \\ m_{j} & \text { mass flow of the jet } \\ m_{m} & \text { mass flow of the mainstream } \\ M R & m_{j} / m_{m} \\ \rho_{j} & \text { density of the jet }\end{array}$

* Research Scientist, Member AIAA

** Senior Laboratory Technician

$\dagger$ Senior Research Engineer, Associate Fellow AIAA

Copyright (C) 1996 by the American Institute of Aeronautics and Astronautics, Inc. No copyright is asserted in the United States under Title 17, U.S.Code. The U.S. Government has a royalty-free license to exercise all rights under the copyright claimed herein for Governmental purposes. All other rights are reserved by the copyright owner.

$\begin{array}{ll}\rho_{m} & \begin{array}{l}\text { density of the mainstream } \\ \text { spacing between corresponding points of } \\ \text { adjacent orifices, e.g. midpoints }\end{array} \\ U_{s} & \begin{array}{l}\text { spatial unmixedness parameter } \\ \text { jet velocity }=m_{j} /\left(\rho_{j} A_{j} C_{d}\right)\end{array} \\ \mathrm{V}_{j} & \text { mainstream velocity }=304.8 \mathrm{~cm} / \mathrm{s} \\ \mathrm{V}_{\mathrm{m}} & \text { root-mean-square of } \mathrm{V}_{\mathrm{m}} \\ \mathrm{V}^{\prime} & \begin{array}{l}\text { downstream coordinate, } \mathrm{x}=0 \text { at the } \\ \mathrm{x}\end{array} \\ \mathrm{y} & \begin{array}{l}\text { leading edge of the orifice } \\ \text { cross-stream coordinate (horizontal) }\end{array} \\ \mathrm{z} & \text { cross-stream coordinate (vertical) }\end{array}$

\section{Introduction}

Crossflow mixing is convenient and efficient for a wide range of applications. Generally the objective is to rapidly obtain a homogeneous mixture of the injectant and mainstream. The appeal of the cross-stream configuration is its effectiveness and simplicity. The degree and rate of the mixing process is especially important in combustion applications since exhaust composition directly depends on mass transfer and reaction kinetics. Whereas kinetics are difficult to control, the mixing process is easily affected by any number of parameters and optimization of that process for combustor design has been the topic of several recent investigations. ${ }^{1-12}$

In this paper the effect of the inlet flow condition of the mainstream on overall mixing performance in a rectangular duct will be discussed. The downstream axial distance of interest is on the order of the duct height. Optimum configurations of jets, that is orifice size and spacing, have been previously identified using isothermal mixing experiments ${ }^{5-12}$ and CFD analysis ${ }^{1-4}$. Those results are based on a homogeneous mainstream and jets that have initially symmetric velocity profiles injected perpendicular to the mainstream. However in practice the initial conditions of both flows are likely to be less controlled. Flow interactions caused by duct geometry and heat release, to mention a few sources, may affect the overall mixing process. The purpose of this investigation is to compare the effects of non-ideal initial conditions on the development of jets in crossflow to previous results. 


\section{Experimental}

Figure 1 is a schematic representation of the apparatus which consists of 3 ducts of rectangular cross section. Sector width is $30.48 \mathrm{~cm}$. The inner duct height $(\mathrm{H})$ is variable, but for these experiments was set at $5.08 \mathrm{~cm}$ at the plane intersecting the row of orifices. The outer ducts which supply the jet fluid are $\mathrm{H} / 2$ in height. The inner and outer ducts are separated by removeable $3.18 \mathrm{~mm}$ thick flat plates which contain the orifice configurations. For all tests near room temperature air was metered by 3 independently controlled critical flow orifices to each of the ducts. The baseline maximum variation in the mean approach velocity of the mainstream was experimentally determined to be $6 \%$ with a turbulence level of $1.3 \%$.

The effect of non-symmetric mass addition was studied by installing different orifice configurations on the top and bottom walls. The data were collected with the baseline mainstream flow condition. Subsequently perforated plates were placed in the mainstream to generate different levels of turbulence intensity $\left(V^{\prime} / V_{m}\right)$. The plates were located $1 \mathrm{H}$ upstream of the plane of the orifice centers. Swirl was investigated by using a 4-swirler bulkhead placed $1.5 \mathrm{H}$ upstream of the plane of the orifice centers. The flowfield induced by the perforated plates and by the swirlers was not experimentally characterized.

Mie scattering was the primary diagnostic used to optically measure jet mixture fraction distributions in planes perpendicular to the duct axis ( $y-z$ plane). The planar digital imaging technique (for more detail see Ref. 13) relies on marking one of the flows with an oil aerosol $(\mu \mathrm{m}$ sized particles). A light sheet $(0.51 \mathrm{~mm}$ thick $)$ created using a $2 \mathrm{~W}$ argon-ion laser and a rotating mirror is used to illuminate a plane in the flowfield after passing through a window in the side wall of the test section. An image intensified thermo- electrically cooled CCD camera, located inside the duct $61 \mathrm{~cm}$ downstream of the orifice center, was focused on the illuminated plane (end-on view). The camera was programmed to make exposures coincident with the sweep of the beam through the flow field. In these experiments the image was digitized in a $516 \times 86$ pixel format (pixel size $=0.58 \mathrm{~mm} \mathrm{x}$ $0.58 \mathrm{~mm} \times 0.51 \mathrm{~mm}$ ) and sent to a computer for storage. The scattered light intensity is proportional to the number of particles in the measurement volume. If only one of two streams is marked, the light intensity of the undiluted marked fluid represents mole fraction unity.

In this study, since the effect of different top and bottom jet mass flows was of interest, the mainstream was marked to avoid the more tedious setup of different marker concentrations for each of the jet flows in the non-symmetric mass addition study. The same setup was also used for the symmetric mass addition configurations. The data reduction procedure was used to reverse the marker location so that the intensity distributions presented are of the jet fluid. All of the reported measurements are mean concentration distributions for 15 second time-averaged measurements.

\section{$\underline{\text { Test Configurations }}$}

The orifice configuration shown end-on in Fig. 2 was used to study the effect of unequal mass addition from opposing sides of the duct, i.e. non-symmetric mass addition. Only the central $2 \mathrm{H}$ section of the $6 \mathrm{H}$ wide duct is shown. The top plate consists of circular $\mathrm{H} / \mathrm{d}=2.67$ diameter orifices spaced $\mathrm{S} / \mathrm{H}=0.50$ on center while the bottom plate consists of circular $\mathrm{H} / \mathrm{d}=4.00$ diameter orifices also spaced at $\mathrm{S} / \mathrm{H}=0.50$ on center. Both of these are optimum orifice configurations for a $J$ of 25 as defined by the correlating expression for directly opposed inline orifices ${ }^{2,6}$ :

$$
\mathrm{C}=(\mathrm{S} / \mathrm{H}) \sqrt{\mathrm{J}}
$$

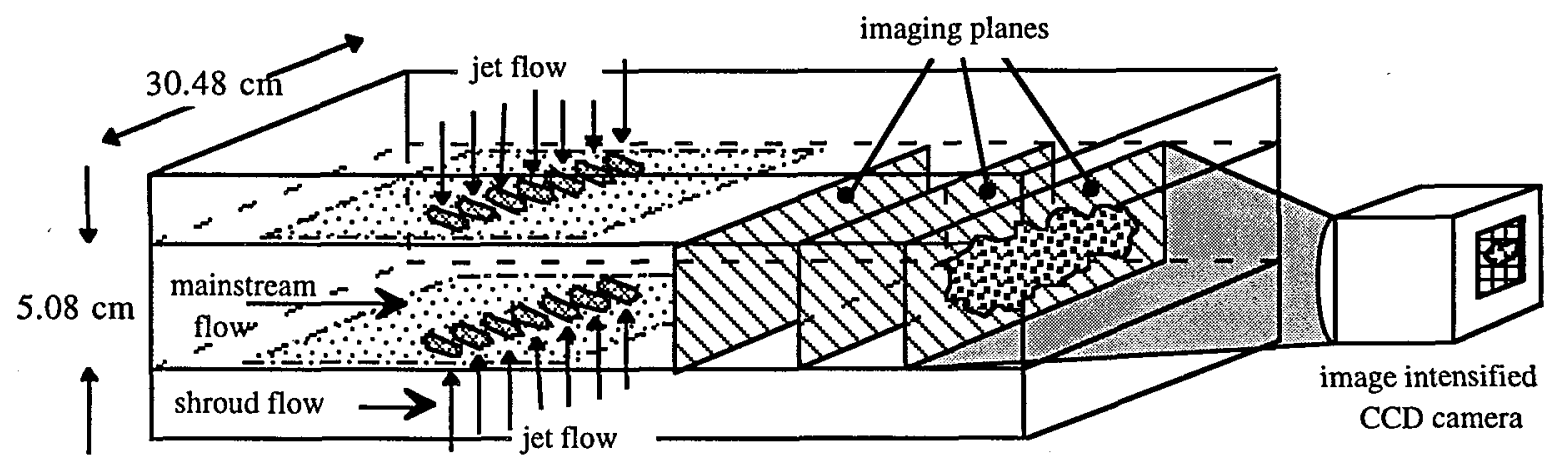

Figure 1: Experimental Configuration used to Measure Planar Concentration Distributions 


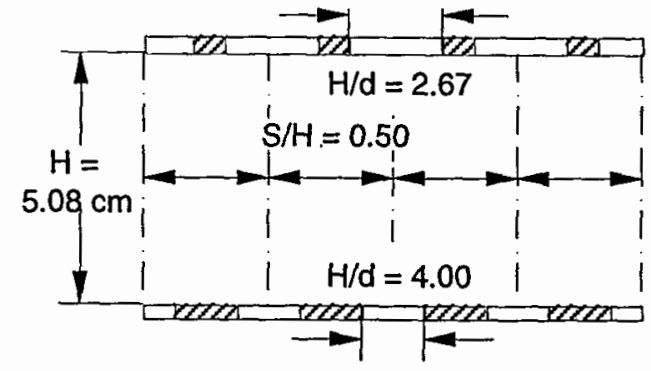

Figure 2: End-on view of the Non-symmetric Mass Addition Orifice Configuration.

The trailing edge of each orifice was inline top-tobottom as shown in Fig. 3. Mainstream flow is from left to right and the location of the downstream measurement planes are shown from the leading edge of the larger orifice, if the orifices on the top and bottom are different sizes.

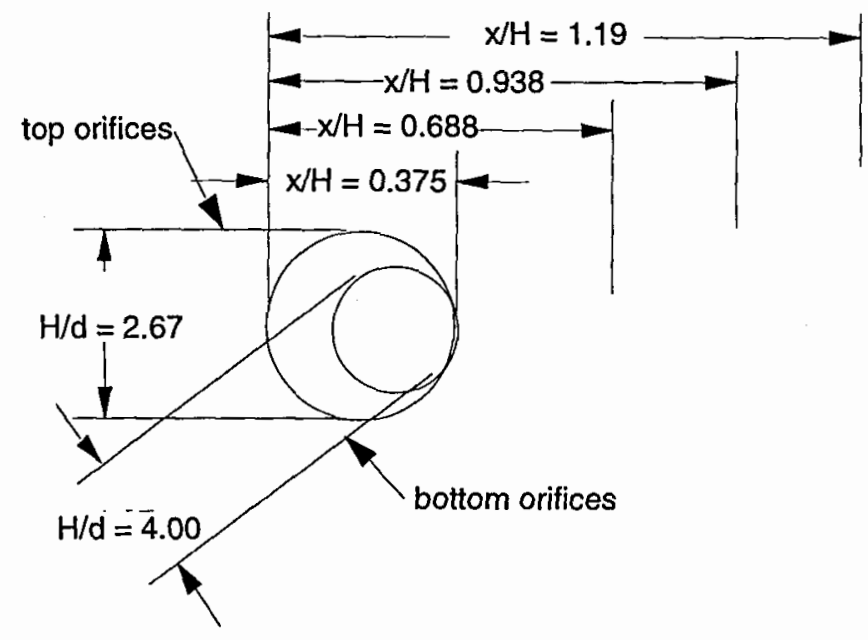

Figure 3: Top view of the Non-symmetric Mass Addition Orifice Configuration.

Table 1 shows the test conditions for the 7 data sets used to illustrate the effect of non-symmetric mass addition. In the first three tests the non-symmetric orifice configuration shown in Fig. 2 is used. In test A, J is constant but the top vs. bottom mass-flow rate varies due to the different orifice areas. In test $C$, the top vs. bottom mass-flow rate is equal while $J$ varies. In test $B$, both mass-flow rate and J vary.

For comparison, the geometric configuration was then made symmetric by placing first circular $\mathrm{H} / \mathrm{d}=2.67$ orifices on both side of the duct (test $D$ and $E$ ) and then circular $\mathrm{H} / \mathrm{d}=4.00$ diameter orifices on both sides of the duct (test $\mathrm{F}$ and $G$ ). In test $E$ and $F$ the opposing $J$ values, and therefore mass-flow from each side, was held constant, while in test $D$ and $G$ the value of $J$ was increased on the bottom row so that about twice the mass flow was introduced from the bottom vs. the top.

The concept of a plane of symmtery between the top and bottom jets was utilized by $\operatorname{Cox}^{14}$ and later Wittig et al. ${ }^{15}$ to allow empirical correlations to be developed for opposed jet injection using single sided injection data. Four different formulations that can be used to split the duct with an imaginary wall at the computed effective duct height $\left(\mathrm{H}_{\mathrm{eq}}\right)$ are listed in Table 1 and defined below:

The first formulation is a momentum-flux ratio balance:

$$
\left[\mathrm{H}_{\mathrm{eq}} / \mathrm{H}\right]_{\mathrm{J} \text {, top }}=[\mathrm{J}]_{\text {top }} /\left([\mathrm{J}]_{\text {top }}+[\mathrm{J}]_{\text {bottom }}\right)
$$

The second formulation is based on Eq. 1,

$$
\begin{aligned}
& \text { (where, } \mathrm{C}=(\mathrm{S} / \mathrm{H}) \sqrt{\mathrm{J}}) \text { : } \\
& \qquad\left[\mathrm{H}_{\mathrm{eq}} / \mathrm{H}\right]_{\mathrm{C}, \text { top }}=\mathrm{C}_{\text {top }} /\left(\mathrm{C}_{\text {top }}+\mathrm{C}_{\text {bottom }}\right)
\end{aligned}
$$

(note that $(\mathrm{S} / \mathrm{H})_{\mathrm{top}}=(\mathrm{S} / \mathrm{H})_{\text {bottom }}$ in all the experiments reported herein so this formulation cannot be separated from one that includes only $\sqrt{\mathbf{J}}$ )

The third formulation is a mass-flow ratio balance:

$$
\left[\mathrm{H}_{\mathrm{eq}} / \mathrm{H}\right]_{\mathrm{MR}, \text { top }}=\mathrm{MR}_{\text {top }} /\left(\mathrm{MR}_{\mathrm{top}}+\mathrm{MR}_{\text {bottom }}\right)
$$

(note that this gives the same answer as Wittig, et al. ${ }^{15}$ when $\mathrm{DR}_{\text {top }}=\mathrm{DR}_{\text {bottom }}$ and $\mathrm{C}_{\mathrm{d} \text {, top }}=\mathrm{C}_{\mathrm{d} \text {, bottom }}$ since $\left.M R=(\sqrt{\mathrm{J}})(\sqrt{\mathrm{DR}})\left(\mathrm{C}_{\mathrm{d}}\right)\left(\mathrm{A}_{\mathrm{j}} / \mathrm{A}_{\mathrm{m}}\right)\right)$

The fourth formulation is the one originally proposed by $\operatorname{Cox}^{14}$ based on a momentum balance:

$$
\left[\mathrm{H}_{\mathrm{eq}} / \mathrm{H}\right]_{\mathrm{Cox}, \text { top }}=\left[\left(\mathrm{A}_{\mathrm{j}}\right)(\mathrm{J})\right]_{\mathrm{top}} /\left(\left[\left(\mathrm{A}_{\mathrm{j}}\right)(\mathrm{J})\right]_{\mathrm{top}}+\left[\left(\mathrm{A}_{\mathrm{j}}\right)(\mathrm{J})\right]_{\text {bottom }}\right)
$$

It follows that:

$$
\left[\mathrm{H}_{\mathrm{eq}} / \mathrm{H}\right]_{\text {bottom }}=1-\left[\mathrm{H}_{\mathrm{eq}} / \mathrm{H}\right]_{\text {top }}
$$

In Table 2 the pattern (at half-scale) and the geometric layout of the turbulence generating perforated plates used to study the effects of turbulence level on mixing performance are shown. Although experimental characterization was not performed, the level of turbulence intensity $\left(V^{\prime} / V_{m}\right)$ indicated was estimated from the correlations found in Ref. 16. Four tests were performed with an orifice configuration consisting of circular $\mathrm{H} / \mathrm{d}=2.67$ diameter orifices spaced $\mathrm{S} / \mathrm{H}=0.5$ on center. The top and bottom plates were equilvalent (Test $E$ in Table 1). Data were only collected at $\mathrm{x} / \mathrm{H}=0.6875$. 


\begin{tabular}{|c|c|c|c|c|c|c|c|}
\hline & Test $\mathrm{A}$ & Test B & Test C & Test D & Test $\mathrm{E}$ & Test F & Test G \\
\hline$[\mathrm{H} / \mathrm{d}]_{\text {top }}$ & 2.67 & 2.67 & 2.67 & 2.67 & 2.67 & 4.00 & 4.00 \\
\hline$[\mathrm{S} / \mathrm{d}]_{\mathrm{top}}$ & 1.33 & 1.33 & 1.33 & 1.33 & 1.33 & 2.00 & 2.00 \\
\hline$[\mathrm{J}]_{\text {lop }}$ & 25 & 25 & 25 & 25 & 25 & 25 & 25 \\
\hline$\left[A_{j} / A_{m}\right]_{\text {top }}$ & 0.22 & 0.22 & 0.22 & 0.22 & 0.22 & 0.10 & 0.10 \\
\hline$[M R]_{10 p}$ & 0.80 & 0.80 & 0.80 & 0.80 & 0.80 & 0.40 & 0.40 \\
\hline$\left[\mathrm{H}_{\mathrm{eq}} \mathrm{d} / \mathrm{H}\right]_{\mathrm{J}, \mathrm{top}}$ & 0.50 & 0.28 & 0.17 & 0.17 & 0.50 & 0.50 & 0.17 \\
\hline$\left[\mathrm{H}_{\mathrm{eg}} / \mathrm{H}\right]_{\mathrm{C}, 10 \mathrm{p}}$ & 0.50 & 0.38 & 0.31 & 0.31 & 0.50 & 0.50 & 0.31 \\
\hline$\left[\mathrm{H}_{\mathrm{OQ}} / \mathrm{H}\right]_{\mathrm{MB}, \mathrm{top}}$ & 0.67 & 0.57 & 0.50 & 0.31 & 0.50 & 0.50 & 0.33 \\
\hline$\left[H_{e q} / H\right]_{c o x, \text { top }}$ & 0.69 & 0.46 & 0.31 & 0.17 & 0.50 & 0.50 & 0.17 \\
\hline$[\mathrm{H} / \mathrm{d}]_{\text {bottom }}$ & 4.00 & 4.00 & 4.00 & 2.67 & 2.67 & 4.00 & 4.00 \\
\hline$[\mathrm{S} / \mathrm{d}]_{\text {bottom }}$ & 2.00 & 2.00 & 2.00 & 1.33 & 1.33 & 2.00 & 2.00 \\
\hline$[\mathrm{J}]_{\text {bottom }}$ & 25 & 65 & 124 & 124 & 25 & 25 & 124 \\
\hline$\left[A_{j} / A_{m}\right]_{\text {bottom }}$ & 0.10 & 0.10 & 0.10 & 0.22 & 0.22 & 0.10 & 0.10 \\
\hline$[\mathrm{MR}]_{\text {bottom }}$ & 0.40 & 0.60 & 0.80 & 1.80 & 0.80 & 0.40 & 0.80 \\
\hline$\left[\mathrm{H}_{\theta \mathrm{q}} / \mathrm{H}\right]_{\text {J, bottom }}$ & 0.50 & 0.72 & 0.83 & 0.83 & 0.50 & 0.50 & 0.83 \\
\hline$\left[\mathrm{H}_{\mathrm{eq}} / \mathrm{H}\right]_{\mathrm{C} \text {, bottom }}$ & 0.50 & 0.62 & 0.69 & 0.69 & 0.50 & 0.50 & 0.69 \\
\hline$\left[\mathrm{H}_{\mathrm{ed}} / \mathrm{H}\right]_{\mathrm{MR}, \text { bottom }}$ & 0.33 & 0.43 & 0.50 & 0.69 & 0.50 & 0.50 & 0.67 \\
\hline$\left[H_{\mathrm{ed}} / \mathrm{H}\right]_{\mathrm{Cox}, \text { bottiom }}$ & 0.31 & 0.54 & 0.69 & 0.83 & 0.50 & 0.50 & 0.83 \\
\hline$A / A_{m}$ & 0.32 & 0.32 & 0.32 & 0.44 & 0.44 & 0.20 & 0.20 \\
\hline MR & 1.20 & 1.40 & 1.60 & 2.60 & 1.60 & 0.80 & 1.20 \\
\hline $\mathrm{C}_{\text {avg }}$ & 0.55 & 0.58 & 0.62 & 0.72 & 0.62 & 0.44 & 0.55 \\
\hline
\end{tabular}

Table 1: Test Conditions used to Illustrate the Effect of Non-symmetric Mass Addition (note that $\mathrm{H}=5.08 \mathrm{~cm}$ in this investigation).

\begin{tabular}{|c|c|c|c|c|c|}
\hline $\begin{array}{c}\text { Plate } \\
\#\end{array}$ & pattern & $\mathrm{H} / \mathrm{d}$ & $\mathrm{S} / \mathrm{d}$ & $\begin{array}{c}\% \\
\text { open }\end{array}$ & $\begin{array}{c}\% \\
V^{\prime} / V_{m}\end{array}$ \\
\hline 1 & $\begin{array}{l}0000000 \\
000000 \\
0000000 \\
000000 \\
0000000\end{array}$ & 12.8 & 1.2 & 65 & 6 \\
\hline 2 & $\begin{array}{c}00000 \\
0000 \\
00000 \\
0000\end{array}$ & 8 & 1.5 & 59 & 12 \\
\hline 3 & $\begin{array}{lllllll}0 & 0 & 0 & 0 & 0 & 0 \\
0 & 0 & 0 & 0 & 0 & 0 \\
0 & 0 & 0 & 0 & 0 & 0 \\
0 & 0 & 0 & 0 & 0 & 0 \\
0 & 0 & 0 & 0 & 0 & 0\end{array}$ & 16 & 2.0 & 21 & 12 \\
\hline 4 & 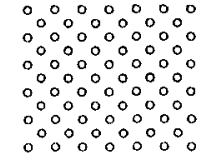 & 32 & 3.5 & 23 & 12 \\
\hline
\end{tabular}

Table 2: Turbulence Generating Perforated Plates 
The effect of upstream swirl was investigated by using a 4-swirler bulkhead. A section of the bulkhead is shown in Fig. 4. The swirl is introduced through a $0.95 \mathrm{~cm}$ annulus of inner radius $2.86 \mathrm{~cm}$. All of the mainstream flow passed through the annular passage and was swirled at $35 \mathrm{deg}$ by the 18 vanes in each of the fixtures. Swirl is imparted in the counter-clockwise direction facing downstream. The bulkhead was located $1.5 \mathrm{H}$ upstream of the jet injection location. The resulting flowfield was not experimentally characterized.

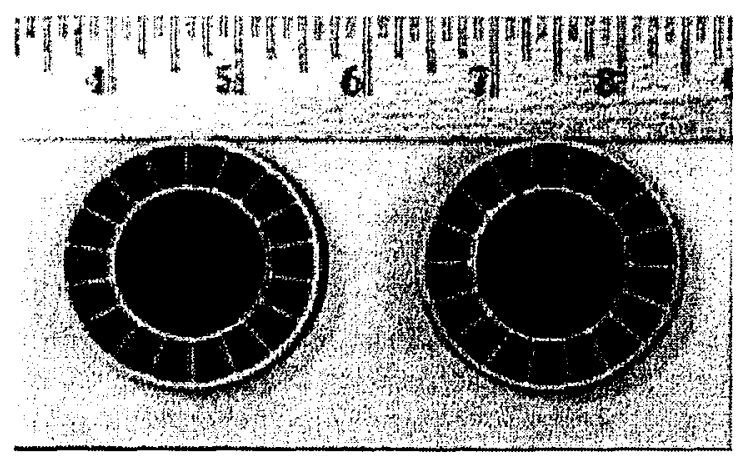

Figure 4: End-on View of the Swirler Bulkhead.

\section{Analysis}

In a two-stream mixing problem the fully mixed concentration is defined by the jet-to-mainstream mass-flow ratio. A measure of the mixing rate can be obtained by comparing the jet mixture fraction distribution at any downstream plane to the fully mixed value. In Ref, 11 the authors discussed a measure of unmixedness based on the variance of the concentration distribution, defined as spatial unmixedness:

$$
\mathrm{U}_{\mathrm{s}}=\frac{\mathrm{c}_{\mathrm{var}}}{\mathrm{c}_{\mathrm{avg}}\left(1-\mathrm{c}_{\mathrm{avg}}\right)}
$$

where,

$$
\begin{aligned}
c_{v a r} & =\frac{1}{m} \sum_{i=1}^{m}\left(\bar{c}_{i}-c_{a v g}\right)^{2} \\
& =\text { spatial concentration variance }
\end{aligned}
$$$$
\overline{c_{i}}=\text { time-average concentration at a pixel }
$$$$
c_{\text {avg }}=\text { fully mixed concentration }
$$

$\mathrm{U}_{\mathrm{s}}=0$ corresponds to a perfectly mixed system, and $\mathrm{U}_{\mathrm{S}}=1$ a perfectly segregated system. The denominator is the maximum concentration fluctuation that can occur at the specified fully mixed concentration. Normalizing by this factor allows $U_{S}$ values to be compared regardless of the jet to mainstream mass-flow ratio of the system. Therefore, this parameter allows comparison of the relative mixing effectiveness of each configuration reported herein and comparison to other configurations with different mass-flow ratios.

\section{$\underline{\text { Results and Discussion }}$}

\section{Non-symmetric mass addition}

In many practical confined mixing applications the duct geometry is not symmetric about a plane that bisects opposing walls, for example in an annulus. However most experimental and computational studies have focused on configurations that are symmetric, i.e. opposing jets are equal in area and momentum-flux ratio $(\mathrm{J})$ and therefore mass addition is symmetric. Correlations that predict optimum mixing performance based on these data sets, such as Eq.1, assume symmetry and generally utilize duct height $(\mathrm{H})$ as a non-dimensionalization parameter. Besides being convenient, $\mathrm{H}$ is important since jet penetration is key to mixing performance. But what if mass addition is non-symmetric? What is the correct value for the equivalent height?

The effect of non-symmetric mass addition is illustrated in Fig. 5 by comparing the jet mass fraction distribution at four downstream locations for test A, B and C in Table 1. A 21-level color scale is used to represent contours of jet mass fraction from 0 to 1.0 (pure mainstream fluid colored red $=0$ and pure jet fluid colored dark blue $=1.0$ ). In each of the tests $(A, B$, and $C)$ the top orifice configuration was identical and about twice the area of the bottom orifice configuration. In test $A$ the opposing values of $J$ are equal but the top vs. bottom the mass flow is not equal due to the different orifice area. The distribution shows a minimum on the duct centerline $(\mathrm{H} / 2)$, which is not surprising since the jet trajectories were optimized for $\mathrm{H} / 4$ penetration using Eq. 1. In test $\mathrm{B}$ the opposing mass flows are unequal and the values of $\mathrm{J}$ are unequal. The minimum in the concentration distribution is now nearer the top of the duct. In test $\mathrm{C}$ the opposing mass flows are equal but the values of $J$ are unequal to obtain the mass balance through the different sized orifices. The values of J are even more mismatched than test $B$ and the minimum in the concentration distribution is even nearer to the top than test $B$.

The results of non-symmetric mass addition test $\mathrm{A}$ is compared to symmetric mass addition tests $\mathrm{E}$ and $\mathrm{F}$ in Fig. 6. All of these tests $(A, E$, and $F$ ) have the same value of $J$ for the top and bottom orifice configurations. The minimum in the concentration distribution is seen to occur on the duct centerline in all cases.

In Fig. 7 tests C, D, and $\mathrm{G}$ are shown. Each test was performed with $J=25$ for the top orifices and $J=124$ for the bottom orifices. Mass addition was symmetric in test $\mathrm{C}$, but non-symmetric in D and G. However The minimum in the concentration distribution is seen to occur near the top of the duct in all cases. 
Two of the $\mathrm{H}_{\mathrm{eq}}$ formulations from Table 1 are plotted on Figs. 5 - 7 at the second downstream location. The solid line corresponds to the $\mathrm{C}$ formulation (Eq. 3) while the dashed line corresponds to the MR formulation (Eq. 4) (note that in Tests D, E, and F the formulations overlap). It appears that the better fit is obtained with the formulation based on Eq. 1, i.e. the value of $\mathrm{H}_{\mathrm{eq}}$ appears to depend on jet penetration which is determined by the product of $\mathrm{S} / \mathrm{H}$ and the square root of $\mathrm{J}$, rather than mass flow. Similar results were obtained by varying opposing values of $\mathrm{J}$ with inline circular $\mathrm{H} / \mathrm{d}=8$ diameter orifices spaced at $\mathrm{S} / \mathrm{H}=0.25$ in Ref. 10 where both experiment and numerical results were reported. Although S/ $\mathrm{H}$ was not varied in either of these investigations the value of $\mathrm{H}_{\text {eq }}$ appears to be independent of orifice diameter.

\section{Mainstream Turbulence}

The influence of several levels of freestream turbulence on the concentration distribution at $\mathrm{x} / \mathrm{H}=0.69$ are compared in Fig. 8. The orifice configuration is symmetric with directly opposed circular $\mathrm{H} / \mathrm{d}=2.67$ orifices spaced at $\mathrm{S} / \mathrm{H}=0.5$. The value of $\mathrm{J}$ on both sides of the duct is 25 which is optimum for this configuration. The observed jet penetrations and mixing performance are similar even through the turbulence level is changed from 6 to $12 \%$ using the perforated plate geometries shown previously in Table 2 . In fact the distributions are similar to the baseline trubulence level of $1.3 \%$ which was shown as test $\mathrm{E}$ in Fig. 6 and is shown again on Fig. 8.

In order for mixing performance to be significantly affected, the penetration of the jet would have to be modified by the different turbulence levels. This is not evident in the data. It appears that the separation point and subsequent formation of the counter-rotating vortices is not affected by the turbulence level of the approach flow, although the data are only available at a single downstream position. This result is in agreement with the single jet experiments of Toften, et al. ${ }^{17}$ where little change in vorticity was measured. It would appear that the vorticity generated by the velocity difference between the jet and mainstream dominates development of the flowfield, which is consistent with the results in Refs. 8 and 9 where neither orifice shape nor downstream tabs had a significant effect on jet penetration or mixing.
Test A

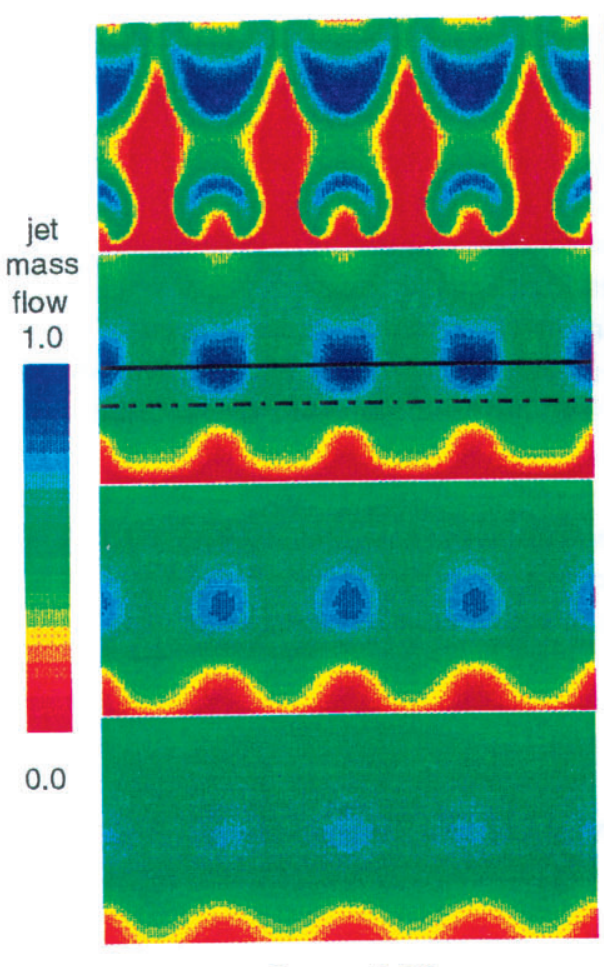

Cavg $=0.55$
Test B
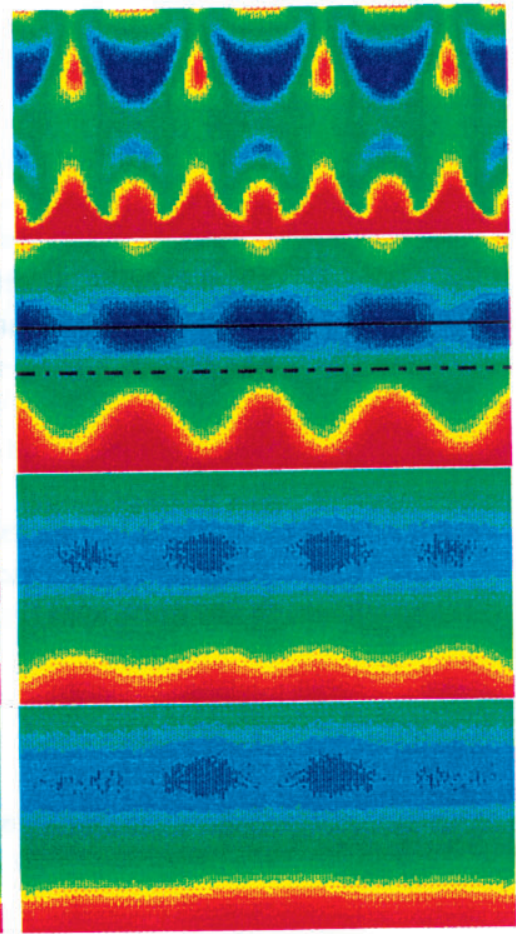

Cavg $=0.58$
Test C

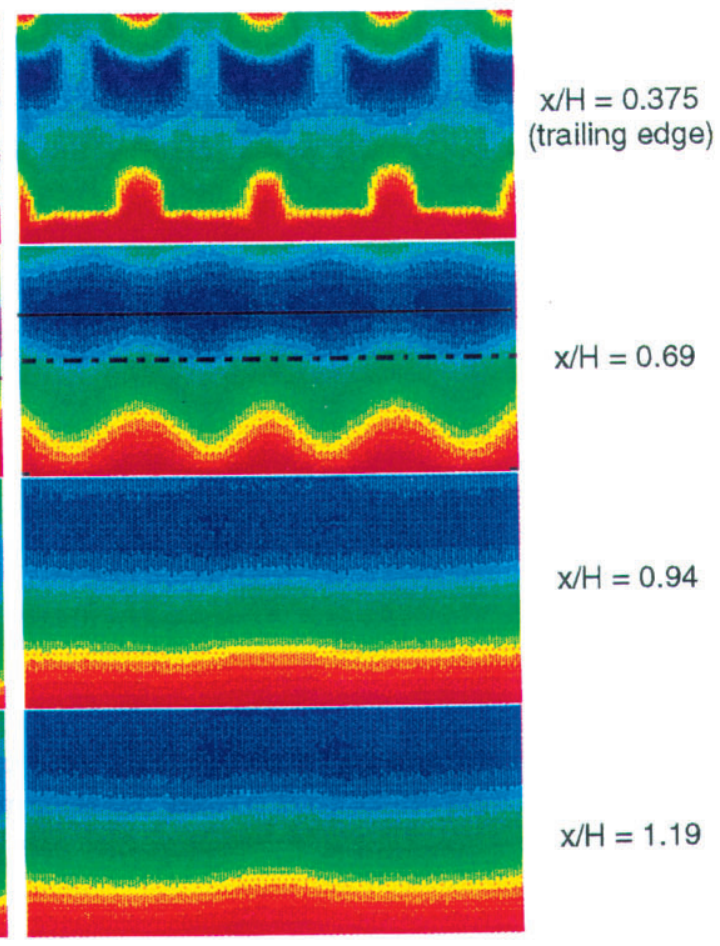

Cavg $=0.62$

Figure 5: Effect of Non-symmetric Mass Addition

(test conditions shown in Table 1) 
Test A

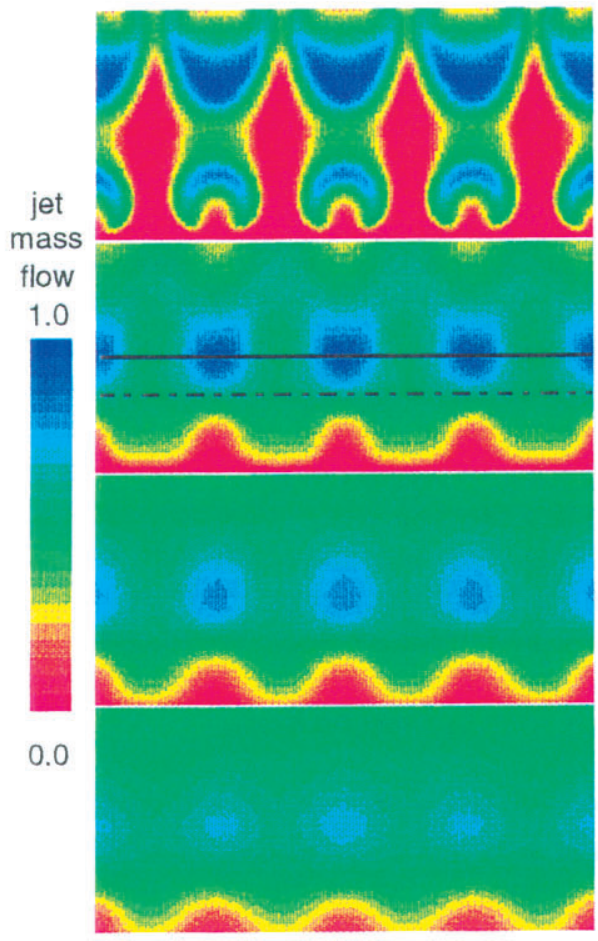

Cavg $=0.55$
Test $\mathrm{E}$
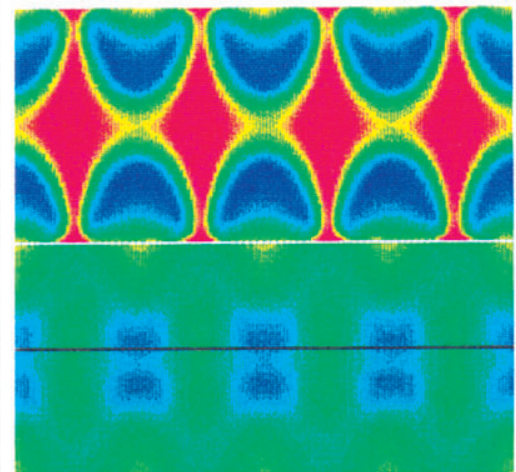

Cavg $=0.62$
Test F

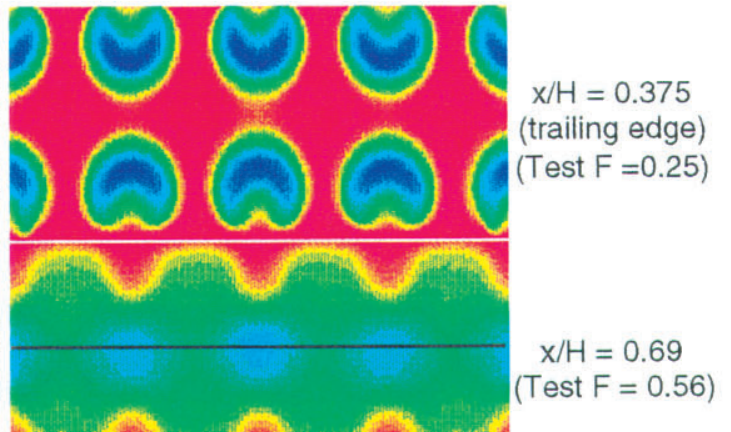

$\mathrm{x} / \mathrm{H}=0.94$

(Test $\mathrm{F}=0.81)$

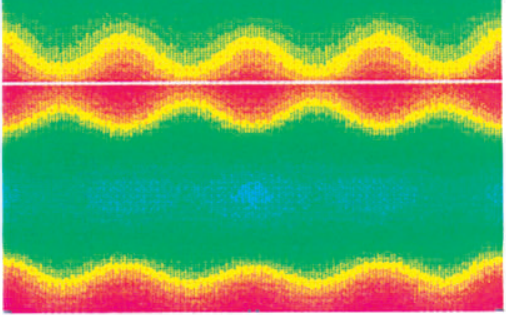

Cavg $=0.44$

Figure 6: Comparison of Non-symmetric to Symmetric Mass Addition (test conditions shown in Table 1)

Test C

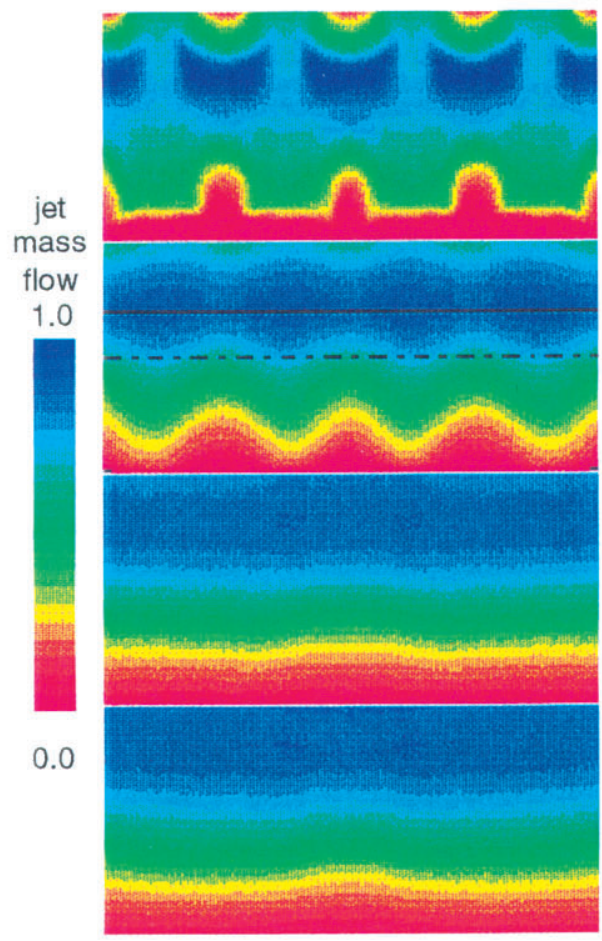

Cavg $=0.62$
Test D

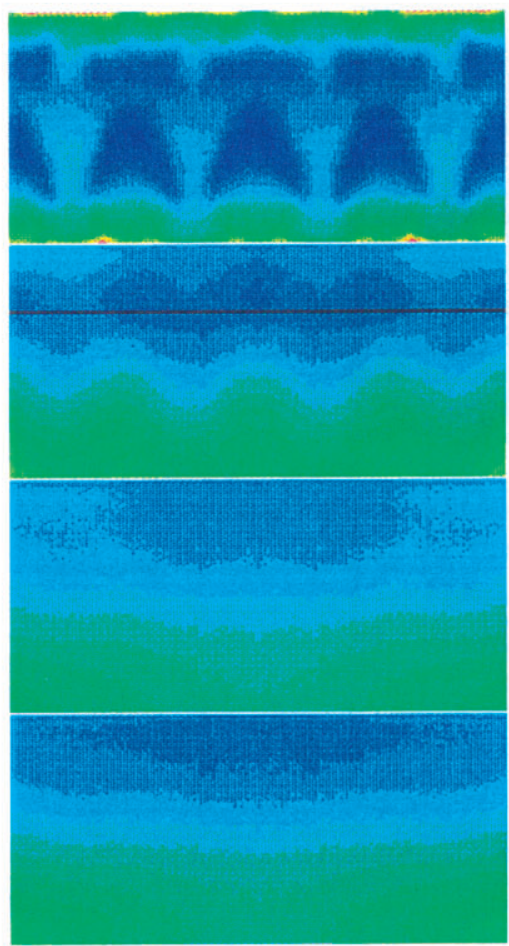

Cavg $=0.72$
Test G

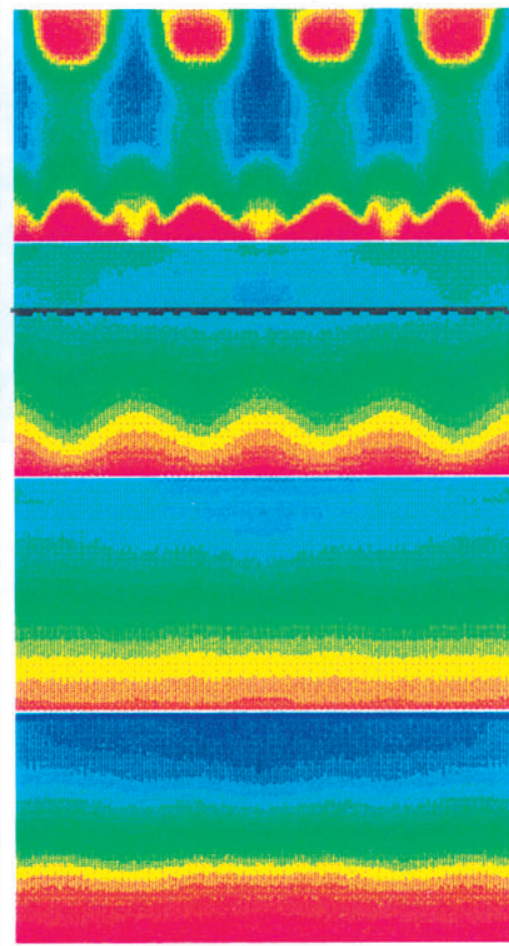

Cavg $=0.55$ $\mathrm{x} / \mathrm{H}=0.375$ (trailing edge) (Test $\mathrm{G}=0.25$ )

$x=0.69$

(Test $\mathrm{G}=0.56$ )

$x / H=0.94$ (Test $\mathrm{G}=0.81$ )

$\mathrm{x} / \mathrm{H}=1.19$ (Test $\mathrm{G}=1.07$

Figure 7: Comparison of Mass Addition at $\mathrm{J}_{\text {top }}=25$ and $\mathrm{J}_{\text {bottom }}=124$ (test conditions shown in Table 1) 


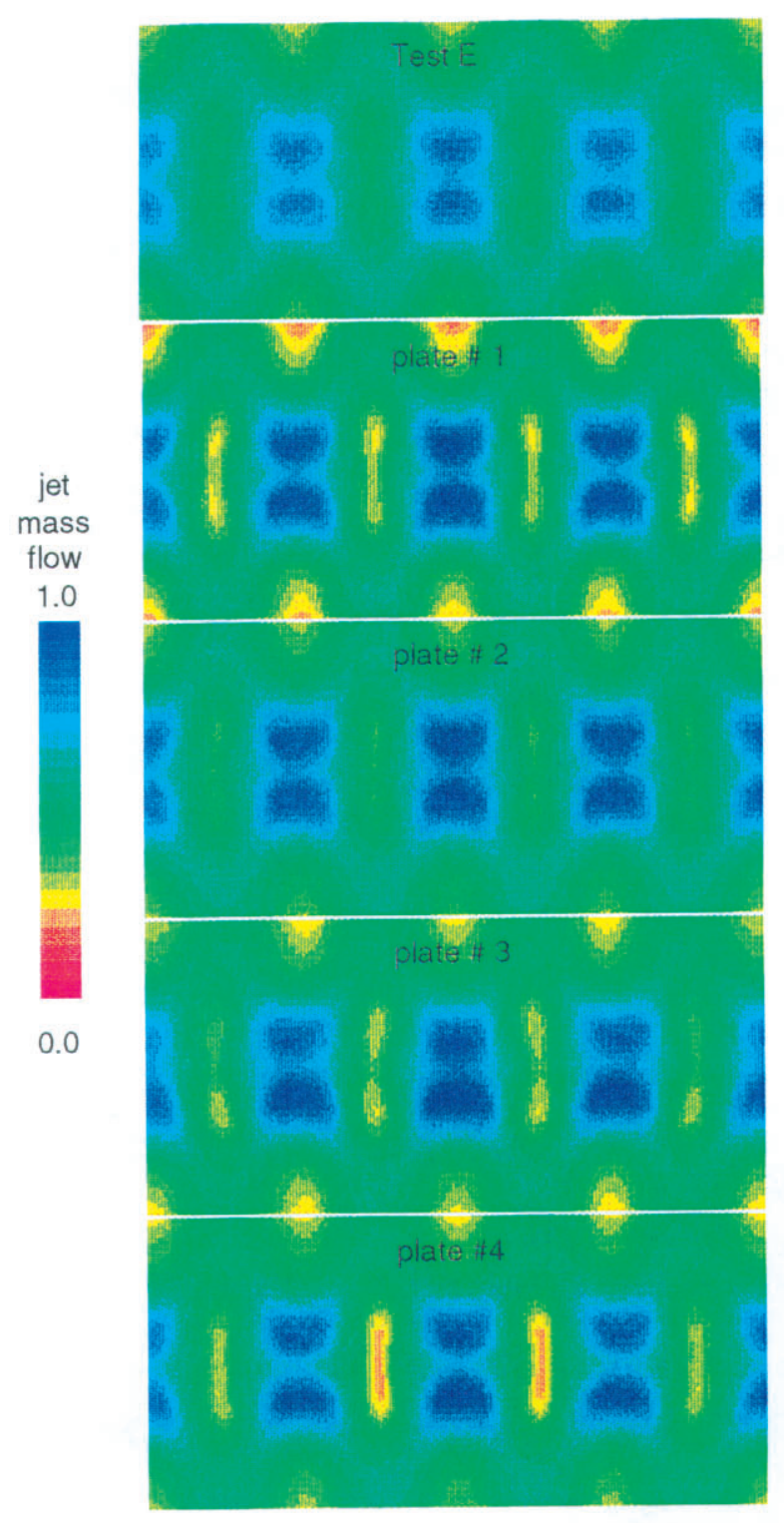

Figure 8: Effect of Mainstream Turbulence on the Concentration Distribution at $\mathrm{x} / \mathrm{H}=0.688$ and $\mathrm{J}=25$ (see Table 1 for Test E and Table 2 for Plate \#1 - 4)

\section{Mainstream Swirl}

The effect of the swirl on the concentration distribution as a function of downstream position for circular $\mathrm{H} / \mathrm{d}=$ 3.70 orifices spaced at $\mathrm{S} / \mathrm{H}=0.36$ at $\mathrm{J}=50$ is shown in Fig. 9 (note that this is an optimum configuration). The effect of the approach flow is evident by the fact that immediately upon injection (trailing edge distribution) the top row of jets lean to the right and the bottom row of jets lean to the left. Farther downstream the "imprint" of the swirler is still evident in the distribution as periodic arrangement of jet fluid centered in the duct and corresponding to the location of the swirlers. The result suggests that the directional vector of the velocity is more important than the turbulence scale. Further work is required to characterize the approach condition and determine whether there is a significant effect on Eq. 1.

In Fig. 10 both the turbulent intensity and swirl spatial unmixedness curves are compared for the data in Figs. 8 and 9. Unfortunately the results of the turbulence level testing is only available at a single downstream position. The spatial unmixedness value for all of those points overlap and show up on Fig. 10 as a overlapping symbols at $\mathrm{x} / \mathrm{H}=0.688$. The results of Test $\mathrm{E}$ are also plotted to compared optimized non-swirled performance to the swirled inlet condition. Although the actual test conditions are not identical, i.e. orifice configuration and $J$ values, the performance should be similar since both orifice configurations are optimized using Eq. 1. It can be seen that the effect of the swirl is a slightly increased mixing rate whereas the turbulence level apparently has little effect. 


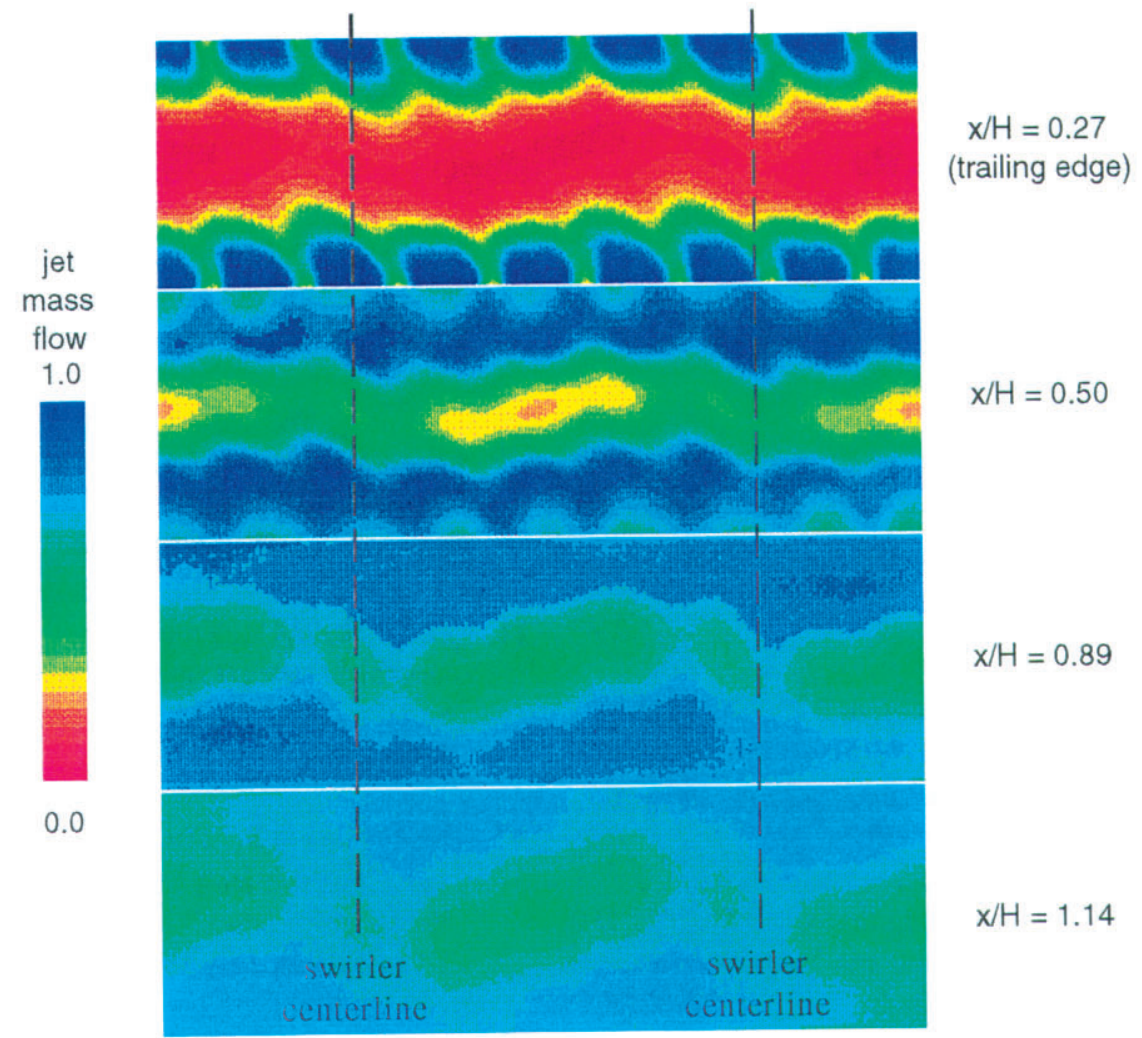

Figure 9: Jet Mass Fraction Distributions Downstream of the Four Swirler Bulkhead

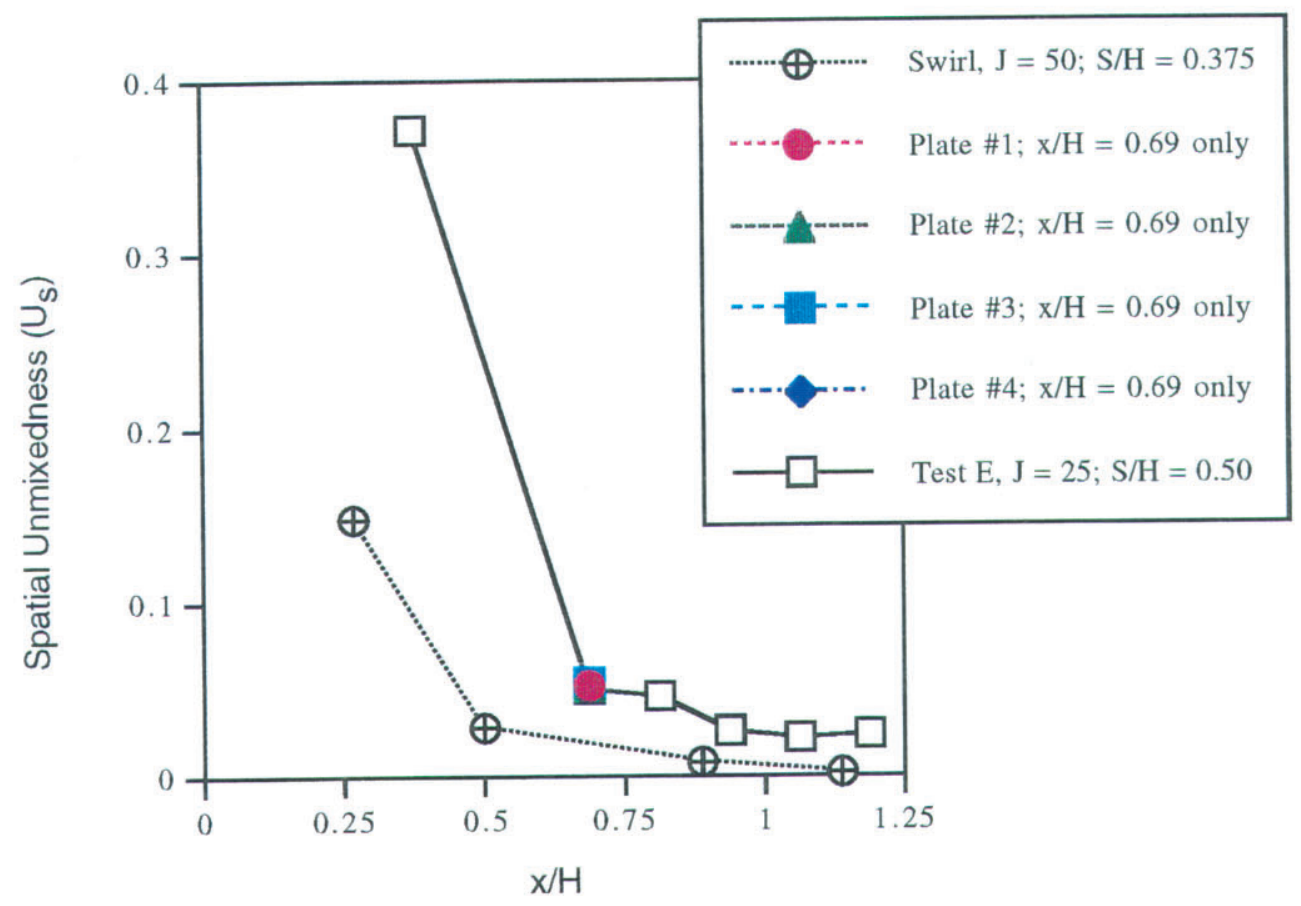

Figure 10: Comparison of the Spatial Unmixedness for the Different Approach Flow Conditions 


\section{Conclusions}

- For non-symmetric mass addition an effective duct height $\left(\mathrm{H}_{\text {eq }}\right)$ based on Eq. 1 can be used to determine the optimum mixing configuration for opposed jet injection.

- Mixing effectiveness for crossflow jets is minimally affected by free-stream turbulence.

- Mainstream swirl can increase crossflow jet mixing rate.

\section{References}

1. Bain, D.B., Smith, C.E., and Holdeman, J.D., "Jet Mixing and Emission Characteristics of Transverse Jets in Annular and Cylindrical Confined Ducts," AIAA 95-2995, (also NASA TM 106976), July 1995.

2. Bain, D.B., Smith, C.E., and Holdeman, J.D., "CFD Assessment of Orifice Aspect Ratio and Mass-flow Ratio on Jet Mixing in Rectangular Ducts," AIAA 94-0218, (also NASA TM 106434), Jan. 1994.

3. Bain, D.B., Smith, C.E., and Holdeman, J.D., "CFD Mixing Analysis of Axially Opposed Rows of Jets Injected into a Confined Crossflow," Journal of Propulsion and Power, 11 (5), pp. 885-893, Oct. 1995, (see also AIAA 93-2044, and NASA TM 106179, June 1993).

4. Bain, D.B., Smith, C.E., and Holdeman, J.D., "CFD Mixing Analysis of Jets Injected from Straight and Slanted Slots into a Confined Crossflow in Rectangular Ducts," AIAA 92-3087, (also NASA TM 105699), June 1992.

5. Doerr, Th., Blomeyer, M., and Hennecke, D.K., "Optimization of Multiple Jets Mixing with a Confined Crossflow," ASME Paper 95-GT-313, 40 ${ }^{\text {th }}$ International Gas Turbine and Aeroengine Congress, Houston, June 1995.

6. Holdeman, J.D., Liscinsky, D.S., Oeschsle, V.L., Samuelsen, G.S., and Smith, C.E., "Mixing of Multiple Jets with a Confined Subsonic Crossflow in a Cylindrical Duct," ASME Paper 96-GT-482, 41 ${ }^{\text {st }}$ Gas Turbine and Aeroengine Congress, Birmingham, U.K., June 1996 (also NASA TM 107185, April 1996).

7. Holdeman, J.D., "Mixing of Multiple Jets with a Confined Subsonic Crossflow," Prog. Energy Combust. Sci., 19, pp. 31-70, 1993 (see also AIAA 91-2458 and NASA TM 104412, June 1991).
8. Liscinsky, D.S., True, B., and Holdeman, J.D., "Crossflow Mixing of Noncircular Jets", Journal of Propulsion and Power, Vol. 12, No. 1 (also AIAA-95-0732 and NASA TM 106865), Jan/Feb. 1996.

9. Liscinsky, D.S., True, B., and Holdeman, J.D., "Effect of Initial Conditions on a Single Jet in Crossflow," AIAA95-2998, (also NASA TM 107002), July 1995.

10. Liscinsky, D.S., True, B., and Holdeman, J.D., "Mixing Characteristics of Directly Opposed Rows of Jets Injected Normal to a Crossflow in a Rectangular Duct," AIAA-940217, (also NASA TM 106477), Jan. 1994.

11. Liscinsky, D.S., True, B., and Holdeman, J.D., "Experimental Investigation of Crossflow Jet Mixing in a Rectangular Duct," AIAA 93-2037,(also NASA TM 106152), June 1993.

12. Liscinsky, D.S., True, B., Vranos, A., and Holdeman, J.D., "Experimental Study of Cross-Stream Mixing in a Rectangular Duct," AIAA Paper 92-3090, (also NASA TM 106194), July 1992.

13. Vranos, A. and Liscinsky, D.S., "Planar Imaging of Jet Mixing in Crossflow," AIAA Journal, 26, 11, pp. 1297-98, Nov, 1988.

14. Cox, G.B., Jr., "An Analytical Model for Predicting Exit Temperature Profile form Gas Turbine Engine Annular Combustors," AIAA 75-1307, Oct. 1975

15. Wittig, S.L.K., Elbahar. O.M.F., and Noll, B.E., "Temperature Profile Development in Turbulent Mixing of Coolant Jets with a Confined Hot Crossflow," Journal of Engineering for Gas Turbines and Power, 106, pp. 193, 1984.

16. Baines, W.D., and Peterson, E.G., "An Investigation of Flow Through Screens," Trans. ASME, pp. 467-480, July, 1951.

17. Toften, T.H., Holdø, A.E., and Kapfer, D, AGARD Meeting on 'Computational and Experimental Assessment of Jets in Cross Flow', pp. 35-1, April 1993.

\section{Acknowledgements}

This work was supported by NASA Contract NAS325954, Task Order \#12 and NASA Contract NAS3-27235, Task 1.0.2.6. 


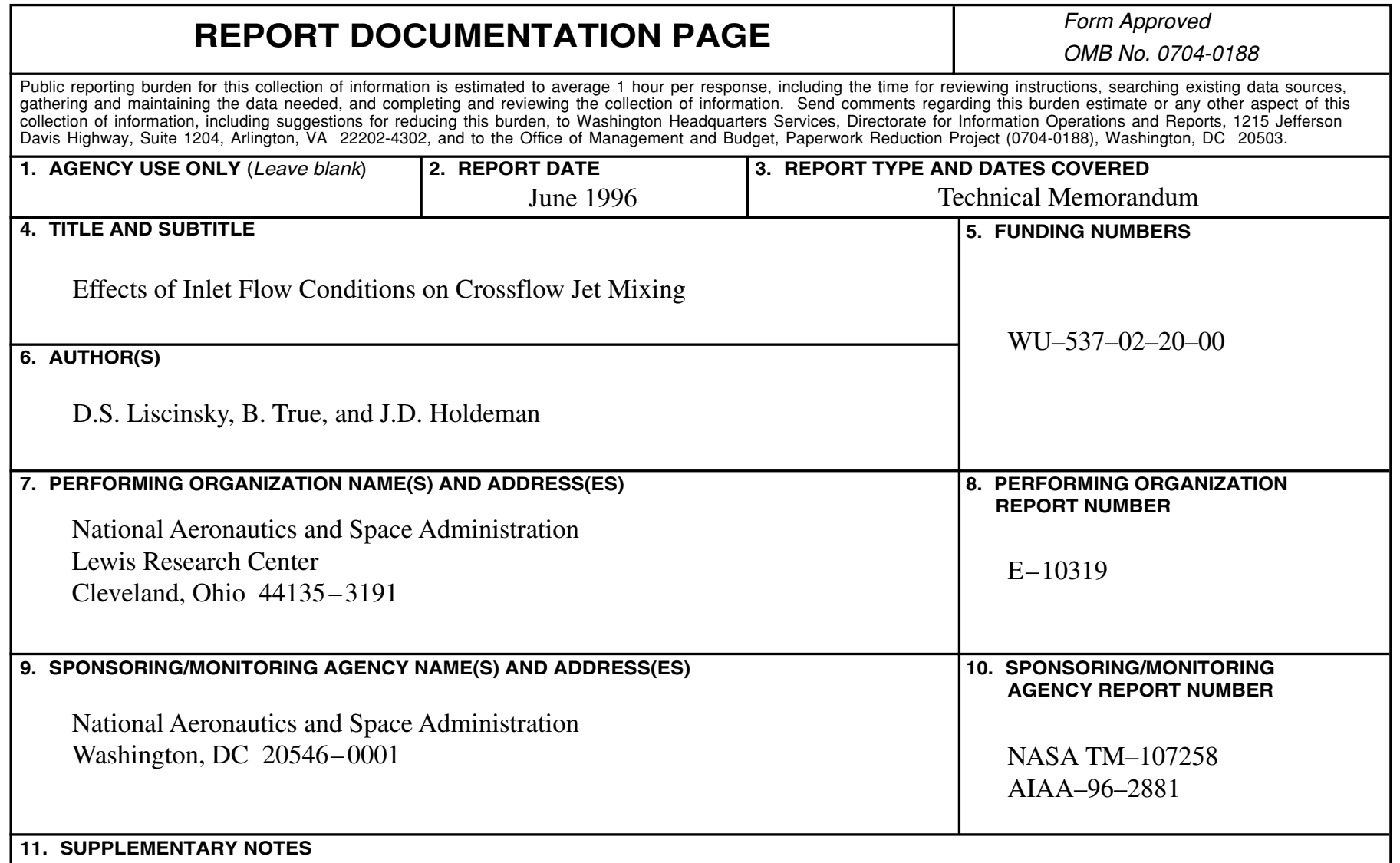

Prepared for the 32nd Joint Propulsion Conference cosponsored by AIAA, ASME, SAE, and ASEE, Lake Buena Vista, Florida, July 1-3, 1996. D.S. Liscinsky and B. True, United Technologies Research Center, East Hartford, Connecticut 06108; J.D. Holdeman, NASA Lewis Research Center. Responsible person, J.D. Holdeman, organization code 2650, (216) 433-5846.

\begin{tabular}{|l|l|l|l|l}
\hline 12a. DISTRIBUTION/AVAILABILITY STATEMENT & 12b. DISTRIBUTION CODE
\end{tabular}

Unclassified - Unlimited

Subject Category: 07

Available electronically at http://gltrs.grc.nasa.gov/GLTRS

This publication is available from the NASA Center for AeroSpace Information, (301) 621-0390.

13. ABSTRACT (Maximum 200 words)

An experimental investigation of the effects of mainstream turbulence, mainstream swirl and non-symmetric mass addition has been conducted for the isothermal mixing of multiple jets injected into a confined rectangular crossflow. Jet penetration and mixing in the near field was studied using planar Mie scattering to measure time-averaged mixture fraction distributions. Orifice configurations were used that were optimized for mixing performance based on previous experimental and computational results for a homogeneous approach flow. Mixing effectiveness, determined using a spatial unmixedness parameter based on the variance of the mean jet concentration distributions, was found to be minimally affected by free-stream turbulence but significantly influenced by the addition of swirl to the mainstream. The results for non-symmetric mass addition indicate that the concentration distribution of the flowfield can be tailored if desired.

14. SUBJECT TERMS

Dilution jet mixing; Gas turbine engine; Combustion chamber; Emissions 15. NUMBER OF PAGES 12

\begin{tabular}{|c|c|c|}
\hline $\begin{array}{c}\text { 17. SECURITY CLASSIFICATION } \\
\text { OF REPORT } \\
\text { Unclassified }\end{array}$ & $\begin{array}{c}\text { 18. SECURITY CLASSIFICATION } \\
\text { OF THIS PAGE } \\
\text { Unclassified }\end{array}$ & $\begin{array}{c}\text { 19. SECURITY CLASSIFICATION } \\
\text { OF ABSTRACT } \\
\text { Unclassified }\end{array}$ \\
\hline
\end{tabular}

